\title{
Regulating Access to Essential Facilities
}

\begin{abstract}
Allan Fels
I t is now six years since Australia's State and Commonwealth Governments introduced the comprehensive reforms which jointly constituted the National Competition Policy. Those six years have left few sectors of the economy unaffected, and have fundamentally changed the nature and philosophy of competition regulation.

Traditional monopolies have been most affected by these changes. While other elements of the National Competition Policy reinforced existing structures in areas such as consumer protection and trade practices, market liberalisation in areas dominated by traditional monopolies was a new phenomenon. As in Europe and a number of other jurisdictions, removing legislative barriers to entry to those markets and regulating access to the essential facilities which delivered the services were the main mechanisms by which this was to be achieved.

Australia's energy, transport and telecommunications markets now operate very differently from the way they did six years ago. The extent and nature of those changes are different in each case. At the same time, the regulations that made them possible are under review by the Productivity Commission, which is currently conducting investigations into both the generic and telecommunicationsspecific access regimes. The Commission released its drafts in March 2001 and will report its findings to the Treasurer at around the time this article goes to press.

This paper outlines the access provisions which now operate in Australia, summarises our experience in implementing them over the last six years, and looks at some of the issues which have emerged as a result of this experience. In particular, issues relating to investment have been prominent in the public debate surrounding the Productivity Commission's inquiry.
\end{abstract}

\section{The Rationale for Access Regulation}

Access by firms to essential facilities has been a fundamental element of the competition reform program. Where structural separation of traditional public monopolies was either not possible or not desirable, and where alternative production facilities are uneconomic to develop, access arrangements were the preferred means of achieving competition in the supply of the final product. Without access arrangements, the other elements of competition policy may not have been sufficient to ensure that the benefits of competition were achieved.

Access regimes recognise that owners of infrastructure facilities may have substantial market power and so be in a position to distort competition in that

Professor Allan Fels AO is the Chairman of the Australian Competition and Consumer Commission. 
market and related markets. Where they are vertically integrated into competitive upstream or downstream markets, service providers may have incentives to restrict competitor access to the services of the facilities in those markets, or to offer terms and conditions of access which discriminate against them. Even when services are vertically separated, the service providers may be in a position to use market power to charge unnecessarily high prices at the expense of consumers and economic efficiency.

The circumstances in which effective competition may not emerge in a market, despite the existence of general competition regulation, are welldocumented. They include:

- So-called 'natural monopolies', where a single operator can produce a product or service at lower unit cost than a number of competing operators. More broadly, significant market power issues may also arise where economies of scale and scope create barriers to entry and limit the number of firms that can operate viably in a market. In such cases, it would be uneconomic for a potential competitor to develop another facility to provide the service.

- Production processes characterised by 'lumpy' and sunk investments. An investment is lumpy if capacity can only be added economically in large increments. It is sunk if it cannot readily be converted to another use. The combination of these characteristics can deter entry and constitute a source of market power.

- Essential' or 'bottleneck' facilities, where the owner is vertically-integrated with potentially competitive activities in upstream or downstream markets. In such circumstances, the potential to charge monopoly prices may be combined with an incentive to inhibit competitors' access to the facility, with clear anti-competitive effects.

- Network externalities, which increase the value of a network to its customers and operators as more customers are added. This may confer substantial competitive advantages on large operators and act as a barrier to entry.

Australia's relatively small markets and dispersed population mean that natural monopoly characteristics are present in most physical distribution networks. While technological change is breaking them down in significant parts of some markets (such as telecommunications), in others (such as power distribution and transport networks) they are likely to persist indefinitely.

Where public monopolies were state-based, the introduction of competition generally required the provision of access to essential facilities by operators based in other states. Cross-jurisdictional access issues are complex. An important objective of the access regime was to ensure that, wherever possible, crossjurisdictional issues were managed in a consistent and transparent manner.

Australia's trade practices legislation contains general provisions concerning the abuse of market power (section 46) covering such practices as refusal to supply and predatory pricing (see Miller, 2001:262-82). The public policy debate 
that preceded the introduction of the access regime focused on the extent to which those provisions provided a sufficient basis for regulating access to essential facilities. It was concluded that, for a number of reasons, s.46 could not adequately address the access problem.

\section{Australia's Access Regimes}

A number of industry and facility-specific access regimes had operated for some time before 1995, including in telecommunications and gas. However, the access regime established by the Competition Policy Reform Act 1995 went well beyond these in providing for the first time an access-specific legislative base with comprehensive coverage. The general provisions were inserted into the Trade Practices Act as a new Part (IIIA) and the telecommunications-specific access regime was established by Part XIC.

Part IIIA attempts to balance the interests of service providers against the interests of service users. The access provisions apply to firms with natural monopoly characteristics that are sometimes vertically integrated and part of network industries. They extend to both privately and publicly owned firms. The regime is intended to be light-handed, and provides for commercial negotiation of access terms and conditions in the first instance. Where access disputes cannot be resolved by the parties themselves, the regime provides for arbitration by the ACCC. The regime includes provision for the enforcement of access determinations and prohibitions on hindering access to a service. Enforcement action is taken in the Federal Court.

The access provisions relate to a range of facilities of national importance. As a single facility may provide a number of services, only some of which may be relevant to the competition objectives, the legislation focuses on services rather than facilities.

Part IIIA provides three mechanisms by which a business, organisation or individual can gain third party access or have third party access available to it. There is a potentially compulsory process under which individual businesses or organisations can seek declaration of a service by the designated Minister. Once declared, a service is effectively regulated, and arbitration is available if the parties cannot agree on any aspect of access. Alternatively, access may be available as a result of a voluntary process whereby a service provider can offer the ACCC an undertaking that sets out the terms and conditions on which it will offer third party access, and which the ACCC may accept. Finally, there may be State and Territory government laws regulating access which can be deemed 'effective' in terms of their compliance with national policy criteria for access laws.

Any person can apply to the National Competition Council for a recommendation to the Minister that a service should be declared. In making a recommendation, the NCC must be satisfied that a service satisfies a number of criteria: 
a) That access (or increased access) to the service would promote competition in at least one market (whether or not in Australia), other than the market for the service;

b) That it would be uneconomical for anyone to develop another facility to provide the service;

c) That the facility is of national significance, having regard to the size of the facility or its importance to constitutional trade or commerce or to the national economy;

d) That access to the service can be provided without undue risk to human health or safety;

e) That access to the service is not already the subject of an effective access regime; and

f) That access (or increased access) to the service would not be contrary to the public interest.

Part IIIA also sets out broad criteria which the Commission is required to take into account in determining terms and conditions of access (including pricing). These include:

a) The legitimate business interests of the provider, and the provider's investment in the facility;

b) The public interest, including the public interest in having competition in markets (whether or not in Australia);

c) The interests of all persons who have rights to use the service,

d) The direct costs of providing access to the service;

e) The value to the provider of extensions whose cost is borne by someone else;

f) The operational and technical requirements necessary for the safe and reliable operation of the facility; and

g) The economically efficient operation of the facility.

The Commission may also take into account any other matters that it regards as relevant.

Since the enactment of Part IIIA, a number of sector-specific arrangements for access have also been developed. These regimes reflect the broad access regulation framework embodied in Part IIIA, but have been further refined to reflect the different technologies, market arrangements, ownership structures and historical regulatory experience of each sector. 


\section{Telecommunications}

A substantial number of reforms have been implemented in the telecommunications market over the last decade, including the introduction of open entry to the market in 1997 (see ACCC, 2001b). The access regime has been a critical component of those reforms.

A limited access regime was in place for telecommunications well before the implementation of Part IIIA. The current telecommunications access regime (Part XIC) was enacted following deregulation of entry into the telecommunications market in July 1997. Consequently, the telecommunications access regime differs in a number of respects from the Part IIIA provisions. It applies a somewhat different test for service declaration (promotion of the long-term interests of endusers, or LTIE test), empowers the Commission itself (rather than the NCC and the relevant Minister) to conduct declaration inquiries and make decisions, and because telecommunications are a Commonwealth responsibility — does not require Federal-State co-regulation.

A number of key telecommunications services that were already being provided were 'deemed' to be regulated in 1997. These services included access to services provided by fixed networks, which can be used to provide longdistance, international and fixed-to-mobile calls, access to services provided on mobile networks, and access to high bandwidth transmission services. The Commission also extended the scope of telecommunications access regulation to broadcasting services over cable networks at that time.

A number of additional telecommunications services were subsequently regulated by the Commission, following a public inquiry in each case. The Commission has recently deregulated some inter-capital transmission services and is now considering whether to deregulate the resale of local calls in central business districts. In both these services, there is evidence that competition has increased over time, so that declaration may no longer be considered to promote the long-term interests of end-users.

\section{Airports}

Like telecommunications, airports are a Commonwealth responsibility and also have a different declaration process than that set out in Part IIIA (see ACCC, 2000:89-96). Services that are necessary for civil aviation operations at an airport and are provided by facilities that cannot be economically duplicated are covered by the access regime. This includes services covered by the price cap as well as freight handling, road access and possibly domestic passenger terminals. Terms and conditions of access to declared services are negotiated between facilities owners and access seekers, with arbitration by the ACCC if negotiations fail.

In addition, and following privatisation of all the major airports except Sydney, the Commission administers a price cap regime for aeronautical services. The services include the provision of certain aircraft movement areas (such as runways and aprons) and passenger processing facilities (such as aerobridges and departure lounges). The price cap allows charges to increase at the general rate of 
inflation minus a component for productivity improvements (commonly referred to as CPI minus X). Within the overall cap, airport operators have significant flexibility to structure their charges. Scope is also provided for airport operators to increase prices to fund necessary new investment without affecting their price cap compliance, following assessment by the ACCC.

\section{Electricity}

The National Electricity Market (NEM), which commenced operation in 1998, operates as a compulsory pool and is governed by the National Electricity Code (NEC). This code was developed jointly by industry, government and regulators in the participating States and Territories, and includes an access regime. The regime is based on the principle of non-discriminatory access for upstream generators and downstream retailers, with NEC provisions specifying connection and augmentation procedures and the methodology for network revenues and prices. The ACCC approved the NEC's access arrangements in the form of an industry code. In accordance with this approval, providers of network services submit an undertaking showing that they will comply with the access provisions.

Under the NEC, the ACCC is the regulator of transmission access and revenues (see ACCC, 2000:66,75-77). The state regulators have jurisdiction over distribution and retail pricing. Some elements of technical regulation (including safety) also reside with state regulators.

\section{Gas}

Broad reforms have been introduced into the natural gas market since 1994 (see ACCC, 2000:63, 66-67, 77-84). The success of these reforms to date has been limited by the failure to achieve competition in gas production. However, access arrangements were set in place early in the process and provide a framework for access to transmission and distribution facilities.

As in electricity, the access arrangements for gas are defined in an industry code jointly developed by the industry, gas users, government and regulators. The Council of Australian Governments (COAG) committed to the National Third Party Access Code for Natural Gas Pipeline Systems (the Gas Code) in 1997. Gas pipeline access regimes for each state and territory are currently being assessed by the NCC to determine whether they are to be certified as effective access regimes under Part IIIA. The COAG agreement also listed a number of gas pipelines that were deemed to be covered under the Gas Code.

The ACCC is the nominated regulator of third party access to gas transmission pipelines in all states and territories except Western Australia (WA), where the state-based regulator has responsibility for both transmission and distribution. In this capacity, the ACCC is responsible for:

- evaluating access arrangements for transmission pipelines (including, among other things, assessing the scope of the services being offered, determining reference tariffs and assessing compliance with ring-fencing requirements); 
- $\quad$ assessing revisions to access arrangements;

- monitoring and enforcement;

- resolving disputes over access to spare capacity or capacity which could be developed;

- $\quad$ approving any contracts between a pipeliner and a related company; and

- $\quad$ approving competitive tendering processes.

Rail

Rail access arrangements are also influenced by a 1997 agreement between the Commonwealth and State governments (see ACCC, 2000:96-99). This agreement provided for the formation of the Australian Rail Track Corporation, whose primary objective was to promote the use of the national rail network by providing a single point of access for rail service providers whose operations cross state jurisdictions. Until then, operators wishing to provide services on the interstate network were required to negotiate access with multiple access providers.

Progress in implementing the reforms has, however, been slow and a national regime has yet to be established. Following a number of inquiries into the sector, the Commonwealth Government has indicated that new regulatory arrangements will be considered if effective access arrangements are not in place later this year.

\section{Benefits of Reform}

Australia's experience in regulating access to essential facilities has been brief. Even the longest established of the industry-specific arrangements is only four years old. While it is clearly too early to make definitive pronouncements on outcomes, it is possible to indicate some of the changes that have already occurred.

The benefits of reform can be indicated by the extent to which retail prices have fallen, service quality has improved, consumer choice has increased and new entry or increased competition has emerged. Indicators of the transparency of regulatory processes and the degree of regulatory accountability might also be considered. Of course, these benefits are associated with the reform process as a whole, not just the access regime.

\section{Prices}

The telecommunications market has seen rapid falls in most categories of retail charges (see ACCC, 2001a). The price falls were earliest and greatest for services first opened to competition (national long distance and international charges), but are now spreading to local services, mobiles and data and Internet services. Access charges for originating and terminating services on the fixed network have fallen by around half since the introduction of the telecommunications access regime. The consumer benefits from retail price falls alone in telecommunications have been estimated by the Australian Communications Authority at between 
$\$ 300$ million and $\$ 400$ million per year (see Collins, McCutcheon and Osiowy, 2000).

In the electricity market, prices have declined greatly since electricity reform commenced (see Port Jackson Partners, 2000 and ACCC, 2000:69-71). Those States which have implemented the reforms have experienced large price reductions. Both New South Wales (NSW) and Victoria have experienced price reductions of around 50 per cent at the wholesale level, while Queensland has shown smaller, but still substantial, falls. However, South Australia has yet to record any price reduction as a result of reforms. Recently, some upward movement in wholesale electricity prices has been observed, reflecting the gradual take up of excess capacity and, in some instances, more commercially oriented bidding strategies by generators.

These price falls have also represented improvements relative to the rest of the world. Australia's average electricity prices have fallen in absolute terms, while those elsewhere tend to have risen. Australia's electricity prices remain low compared to other industrialised nations.

Gas prices have shown less change than electricity prices during the postreform period, largely because of the slower progress of the reform process in gas than in electricity. Where gas prices have fallen (for example, in WA), other factors influencing the degree of competition in the upstream market are likely to have been important. In WA, these included competition among a number of gas fields owned by different joint ventures to supply the market, and the disaggregation by the WA government of the single dominant supply contract with the North West Shelf Joint Venture.

The CPI minus $\mathrm{X}$ price cap imposed on regulated airports is providing significant benefits for users. The price cap has delivered reductions in landing charges in real terms at all the regulated leased airports. The reductions are expected to be as high as 22 per cent over the five years of the price cap.

The extent of the price falls reflects the achievement of production efficiencies as a result of increased competition and, in some cases, the transfer of above-normal profits from infrastructure owners to their wholesale and retail customers.

\section{Non-price service attributes}

Changes in price must also be seen in the light of various quality changes associated with the reforms, and relevant indicators vary across the industries. For example, in telecommunications the Australian Communications Authority publishes an annual Telecommunications Performance Report and quarterly Performance Monitoring Bulletins, providing very detailed and comprehensive information on non-price service attributes. In other industries the risk of shortterm price and supply fluctuations has also been reduced as competition has introduced alternative sources of supply. For example, the National Electricity Market allows for vesting contracts and an active bilateral market permitting retailers to hedge load obligations. Such arrangements are likely to avoid the 
emergence of problems such as those recently experienced in California, where retailers buying their electricity in the wholesale market at variable rates, but selling at capped rates, found that tight supply and the recent rise in fuel prices had combined to force wholesale prices above retail prices.

\section{Consumer choice}

Most telecommunications customers now have the choice of several providers for a number of telecommunications services. Multi-utility operators are emerging in several telecommunications and energy markets, and are planning to offer bundled service packages to consumers in attractive pricing deals.

Retail contestability has been achieved for medium to large industrial and commercial electricity customers in the National Electricity Market, and full retail contestability is scheduled for the end of 2002. Retail contestability for gas customers is expected to be implemented in NSW and Victoria later this year.

\section{Other pro-competitive developments}

In some industries, the introduction of access regulation has coincided with structural reforms. Structural reforms, particularly vertical separation, reduce the inherent disincentives for denial of access and improve the ability of the market itself to generate good outcomes with limited direct involvement from the regulator.

Structural separation of electricity generation, transmission and distribution functions has occurred in all states and territories in the National Electricity Market, although in some states facilities remain in government ownership. Government-owned gas transmission and distribution activities have also been separated in all states, while legislation requires ring-fencing of activities in privately-owned firms in all states. Rail track access and freight activities have also been structurally separated in all states.

The incumbent telecommunications operator, Telstra, has not been required to separate its carriage services from its other functions. Consequently, access arrangements are particularly important in that sector. The Productivity Commission's terms of reference do not extend to consideration of structural separation of Telstra, although it is considering accounting separation and has suggested a legislated pricing principle requiring non-discrimination between inside and outside access seekers (see Productivity Commission, 2001b:10.17).

In some markets, technological and service innovations have also coincided with the introduction of access regulation. This is particularly the case in telecommunications, where the development of high-bandwidth capabilities, wireless technologies and providers capable of offering telephone, television and data services in bundled packages are changing cost structures in a number of markets. In such cases, the forces for change have compounded, and outcomes cannot easily be attributed to any individual factor. 


\section{Processes}

Translating the legislative principles into operational access regimes has produced its own challenges. Some of the problems are inherent in the regulatory task. Others reflect the particular characteristics of the regulated markets.

In particular, regulators face difficult trade-offs between the simplicity and timeliness of decisions, and 'getting the decision right'. Delays in reaching decisions increase uncertainty over regulatory outcomes which influence major market parameters. However, decisions concerning pricing, rates of return and other financial indicators generally require close scrutiny of detailed cost and other information, as well as a good understanding of the technical aspects of production, interconnection and distribution. Errors in such decisions may be costly to market participants and, if they are of sufficient magnitude, may even compromise the longer-term benefits of the reforms. Where limited regulatory intervention is required, this is unlikely to be a concern. Unfortunately, our experience in telecommunications, where access providers and access seekers have frequently been unable to reach commercial agreements concerning the terms and conditions of access, has meant that the Commission has been required to arbitrate a large number of access disputes and so has become the de facto pricesetter for a number of major access services.

\section{Regulation, Operational Efficiency and Investment}

Access regulation influences market structure, constrains market behaviour and, in many cases, establishes the terms and conditions on which business is done in a market. Regulation can alter the ability of firms to invest in an industry and the returns they can expect from doing so. Regulations concerning the price at which services must be traded are particularly relevant to the investment decisions of both access providers and access seekers, and can have a potentially significant impact on the level and mix of investment in affected industries.

In exercising its responsibilities, the Commission has been particularly concerned to ensure that its pricing determinations not only provide positive incentives to improve efficiency, but also appropriate disincentives for inefficiency and poor service quality. Prices based on firms' actual costs do not necessarily deliver such incentives.

Incentive regulation, as applied by the Commission, works on two levels. First, it encourages operators to reduce their costs in any given regulatory period. If the provider realises cost savings in that period, it retains those savings. Second, where revenue caps operate to restrict revenue per unit of output, an operator who is able to increase volume above the forecast level is able to retain the benefit of that market growth. The overall effect is to encourage operators to maximise profits by making efficiency gains and growing the market. These gains can then be shared with consumers in the longer term.

With these issues in mind, the Commission has adopted a 'building block' approach to pricing determinations in a number of regulated industries. Under this 
approach, forecasts are made of the cost of service over the regulatory period and total revenue is calculated as the sum of the return on capital, depreciation, and operating and maintenance expenditure. However, determining the individual elements of the 'building block' raises significant issues with respect to providing service providers with a fair and reasonable return, while at the same time promoting economic efficiency.

Taxation and the treatment of depreciation have been two particularly difficult questions. The Commission has consulted widely on its approaches to these matters. It has concluded that its approach to regulatory assessments should be tax-inclusive, and based on a post-tax framework which provides a nominal return to equity invested. The Commission believes that weighted average cost of capital (WACC) determinations are better understood by financial markets when expressed in post-tax, nominal terms than the pre-tax real terms.

The Commission has also proposed the use of a competitive depreciation profile, allowing a smoothing of revenue paths to avoid inter-generation pricing disparities and adjustments to reflect the impact of future potential stranding of assets. This approach is preferred to traditional linear depreciation schedules, as it links the long-term depreciation profile to a measure of the rate of technological change, minimises price distortions caused by inter-generation price shocks over time and minimises potential geographical price distortions linked to the age of assets serving neighbouring systems.

In telecommunications, the concept of efficient forward-looking costs has been applied. For services provided by the public switched telephone network, the Commission models 'total service long run incremental cost' for the purpose of determining terms and conditions of access to declared services in the public switched telephone network (PSTN). Again, critical elements of these costs, including efficient network configuration, depreciation and approaches to risk have raised difficult issues, on which the Commission has sought expert advice and engaged in extensive consultation. Access pricing in telecommunications also illustrates the breadth of the constraints under which the Commission operates. In particular, nearly half of the price for access to the PSTN is an 'access deficit contribution' included to assist Telstra in recouping the loss it makes on providing line rentals, the prices of which are restricted by retail price controls.

The claim is frequently made that the Commission's pricing determinations do not provide sufficient return to investors and are restraining the development of new infrastructure. This has been a particular concern in the Productivity Commission's inquiries into the operation of Parts IIIA and XIC. As the Productivity Commission notes, this is a difficult issue because it is necessary to establish the counterfactual - that is, what would have been the level and pattern of investment in the absence of the regulation?

With respect to rates of return, work was recently commissioned from National Economic Research Associates (n/e/r/a, 2001) to assess regulatory levels of WACC set in other jurisdictions. While such international comparisons must be interpreted carefully, the $\mathrm{n} / \mathrm{e} / \mathrm{r} / \mathrm{a}$ study did not provide any evidence that the Commission has been setting relatively low rates of return. 
With respect to investment volume, evidence assembled by the ACCC shows that investment in regulated industries has continued at robust levels, and, on the surface, is not the cause of any immediate concern. For example, new electricity generation facilities have been brought online in Queensland and Victoria. A major new gas pipeline is operating in Eastern Australia. Major new investments are being undertaken at a number of regulated airports.

In telecommunications there is evidence of strong investment by both Telstra and by new entrants. This is detailed in the ACCC's response to the Productivity Commission's Draft Report, available on the Productivity Commission's web-site. Perhaps if the record had been one of falling or even static investment by Telstra, the extent of the Productivity Commission's concern could have some basis. As it stands, it is difficult to accept the Commission's claim of being 'unable to determine' whether investment has been damaged 'so far'. It clearly has not been. When the record on the flow of investments outside of Telstra is examined, there is evidence of strong investments especially in mobiles, fibre optics, xDSL, and LMDS. This is based on information gathered in a recent survey of more than 50 carriers conducted for the ACCC by BIS Shrapnel (2001).

\section{Conclusion}

The effectiveness of access regulation, as for all regulation, must ultimately be judged by its outcomes. Consequently, the Commission has adopted a watchful approach in an effort to ensure that regulation continues to secure the objectives required by the legislation. In our experience, where difficulties have arisen, they appear largely transitional in nature, or are the result of factors outside the access regime itself. In some cases, the Commission has suggested amendments to the operational arrangements that may enable them to achieve their objectives in a faster, more cost-effective and transparent way. Further, the ACCC has been an active participant in the year-long debate surrounding the Productivity Commission's inquiries.

The reasons for intervening in the industries covered by this paper - gas, electricity, telecommunications, airports and rail - is that there is natural monopoly power that would lead to unsatisfactory outcomes in its absence. In general, the Commission is satisfied that the framework for access regulation laid down in the legislation and codes appears to be robust, and that its approaches to declaration and coverage and to access pricing balance the interests of suppliers and consumers and provide the right incentives for efficient industry development.

In contrast to this view, those with an interest in weakening the access regime have expended vast resources in their quest to avoid coverage and to have the ability to charge much higher access prices, including in their approaches to the Productivity Commission. The view the ACCC has put to the Productivity Commission is that, while the regimes are still in a fairly early stage, the Commission's experience does not suggest that they require fundamental revision of either the tests for declaration or coverage of facilities essential to fostering competition or the procedures for the setting of access charges. In the ACCC's 
view, a strong enough case has not been made for basic changes to a regulatory structure that has appropriately enhanced the well-being of Australians.

\section{References}

ACCC (2000), Annual Report 1999-2000, AusInfo, Canberra.

ACCC (2001a), Changes in the Prices Paid for Telecommunications Services in Australia 1996-97 to 1999-2000, Melbourne, April.

ACCC (2001b), Infrastructure Industries Telecommunications, Melbourne, May.

BIS Shrapnel (2001), Telecommunications Infrastructures in Australia 2001, Research Report prepared for the ACCC, Melbourne, July.

Collins, P., M. McCutcheon and E. Osiowy (2000), Benefits to Consumers of Telecommunications Services in Australia 1995-96 to 1999-2000, Report prepared for the Australian Communications Authority.

Miller, R. (2001), Miller's Annotated Trade Practices Act 2001, $22^{\text {nd }}$ edition, LBC Information Services, Sydney.

National Economic Research Associates (2001), 'International Comparison of Utilities Regulated Post-tax Rates of Return in North America, the UK, Northern Ireland and Australia', Report prepared by n/e/r/a for the ACCC, Sydney, March.

Port Jackson Partners (2000), 'Australia's Energy Reform: An Incomplete Journey', Report to the Business Council of Australia, 14 March.

Productivity Commission (2001a), 'Review of the National Access Regime', Position Paper, Canberra, March.

Productivity Commission (2001b), Telecommunications Competition Regulation, Draft Report, Canberra, March.

The author gratefully acknowledges the useful comments of two anonymous referees. This is a revised and updated version of a paper presented in February 2001 to the Directorate-General for Competition, European Commission, Brussels. 